\title{
Positive predictive value of a case definition for diabetes mellitus using automated administrative health data in children and youth exposed to antipsychotic drugs or control medications: a Tennessee Medicaid study
}

William V Bobo ${ }^{1 *}$, William O Cooper ${ }^{2}$, C Michael Stein $^{3}$, Mark Olfson ${ }^{4}$, Jackie Mounsey ${ }^{1}$, James Daugherty ${ }^{5}$ and Wayne A Ray,

\begin{abstract}
Background: We developed and validated an automated database case definition for diabetes in children and youth to facilitate pharmacoepidemiologic investigations of medications and the risk of diabetes.

Methods: The present study was part of an in-progress retrospective cohort study of antipsychotics and diabetes in Tennessee Medicaid enrollees aged 6-24 years. Diabetes was identified from diabetes-related medical care encounters: hospitalizations, outpatient visits, and filled prescriptions. The definition required either a primary inpatient diagnosis or at least two other encounters of different types, most commonly an outpatient diagnosis with a prescription. Type 1 diabetes was defined by insulin prescriptions with at most one oral hypoglycemic prescription; other cases were considered type 2 diabetes. The definition was validated for cohort members in the 15 county region geographically proximate to the investigators. Medical records were reviewed and adjudicated for cases that met the automated database definition as well as for a sample of persons with other diabetes-related medical care encounters.

Results: The study included 64 cases that met the automated database definition. Records were adjudicated for 46 (71.9\%), of which 41 (89.1\%) met clinical criteria for newly diagnosed diabetes. The positive predictive value for type 1 diabetes was $80.0 \%$. For type 2 and unspecified diabetes combined, the positive predictive value was $83.9 \%$. The estimated sensitivity of the definition, based on adjudication for a sample of 30 cases not meeting the automated database definition, was 64.8\%.
\end{abstract}

Conclusion: These results suggest that the automated database case definition for diabetes may be useful for pharmacoepidemiologic studies of medications and diabetes.

Keywords: Type 2 diabetes, Computer case definition, Health administrative data, Validity, Positive predictive value

\footnotetext{
* Correspondence: william.v.bobo@vanderbilt.edu

${ }^{1}$ Department of Psychiatry, Vanderbilt University School of Medicine, 1500 21 st Ave South, Suite 2200 Village at Vanderbilt, Nashville, TN, 37212, USA Full list of author information is available at the end of the article
} 


\section{Background}

The pronounced increase in adolescents and young adults of the incidence of type 2 diabetes $[1,2]$ has stimulated interest in the epidemiology of diabetes in this population. Factors of interest include genetic characteristics $[3,4]$, diet $[5,6]$, lifestyle $[7,8]$, environmental factors [9], and prescribed medications [10-12]. Given that type 2 diabetes is a chronic disease with serious health consequences [13-15], there is an urgent need to better understand its pathophysiology so that appropriate preventive measures can be devised in this vulnerable population. Although it is an important public health problem, medication-associated type 2 diabetes occurs infrequently. Clinical trials and prospective cohort studies are unlikely to have sufficient power or duration of followup needed to detect important inter-drug differences in type 2 diabetes risk, and will often exclude vulnerable populations such as children and youth.

Large automated databases of medical care encounters are therefore a valuable resource for observational studies of the epidemiology of medication-associated type 2 diabetes in children and youth. Database records of inpatient and outpatient medical care encounters allow efficient identification of newly diagnosed cases of diabetes for large populations. They are particularly valuable for studies of medications, as databases include computerized prescription records, which provide objective, detailed, reliable and relatively low-cost measures of drug exposure [16]. Database records of medical encounters may also allow identification of newly diagnosed cases of type 2 diabetes. However, these records are subject to misclassification $[17,18]$, including identification of existing (rather than newonset) diabetes, which may introduce bias that cannot be overcome using statistical adjustment or other data analytic techniques. A reliable computer case definition is therefore essential for conducting studies of newly diagnosed type 2 diabetes associated with medication exposure using automated databases.

Thus, we utilized a sample from an in-progress retrospective cohort study in Tennessee Medicaid enrollees 6-24 years of age who were treated with atypical antipsychotic drugs or control medications to develop and validate a case definition for newly diagnosed diabetes suitable for automated databases.

\section{Methods}

\section{Sources of data}

The automated database case definition was part of an in-progress retrospective cohort study of antipsychotics and the risk of type 2 diabetes among children and youth enrolled in Tennessee Medicaid [18]. Computerized Medicaid files include an enrollment file as well as files recording prescriptions filled at pharmacies, hospital admissions, outpatient visits, and long-term care residence. The Medicaid files have been augmented by linkage with computerized death certificates [18] and, since 1998, with the State Hospital Discharge File, a comprehensive, statewide database of hospital discharges and emergency department visits, which provides information occasionally missing from Medicaid files. These files permitted identification of both the study cohort and the medical care encounters used to identify potential diabetes cases $[16,18]$.

Tennessee Medicaid is an expanded version of the joint federal-state Medicaid program that finances medical care for qualifying low income persons. Expansions in 1994 extended Medicaid to include previously uninsured persons. Tennessee Medicaid enrollees had no deductible, co-pay, or prescription limits for most of the study period. In 2005, a five prescription per month limit (of which only two prescriptions could be for brandname drugs) was enacted. However, this requirement did not apply to children or youth under 21 years of age. Furthermore, diabetes medications (insulin preparations and oral hypoglycemics) and diabetic supplies were considered exempt (i.e., did not count toward the prescription limit) during the entire study period, and none of the diabetes drugs could be obtained over-the-counter. Thus, data were considered complete for diabetes prescriptions and supplies used as components of the diabetes computer case definition (discussed below).

Children and youth eligible for the cohort were 6 to 24 years of age and enrolled in Tennessee Medicaid at some time between 1 January 1996 and 31 December 2007. Cohort membership also required at least one year of prior enrollment (with respect to time zero, the first day in which the cohort member satisfied all of the inclusion and exclusion criteria for a recent initiator of study medications, as discussed below), during which there was medical care utilization and full prescription drug coverage (allowing lapses of $\leq 7$ days), which maximized availability of data needed for study variables. The cohort excluded persons with life-threatening illness, institutional residence, diagnosed schizophrenia or related psychosis or other condition for which antipsychotics are the only recommended treatment, medical care indicating diabetes (including ICD-9-CM codes consistent with a diagnosis of diabetes and/or filled prescriptions for diabetes medications), pregnant women (because gestational diabetes might be misdiagnosed) or women with diagnosed polycystic ovarian syndrome (treated with oral hypoglycemics). Cohort members could not have been in the hospital in the past 30 days because Medicaid files do not include in-hospital medications.

The cohort consisted of eligible recent initiators of antipsychotics or other psychotropic drugs (mood stabilizers, attention-deficit hyperactivity disorder drugs, 
selective serotonin reuptake inhibitor and related antidepressants, benzodiazepines). Recent initiators filled a qualifying prescription for a study drug on a day of cohort eligibility, with no prescription fill for a study drug in the preceding 365 days. Cohort members could also have non-qualifying use of study drugs in the 90 days preceding the qualifying prescription to allow inclusion of patients starting a study drug shortly after a hospital discharge; however, for cohort members who filled a study drug prescription within this 90 day window, there had to be no filled prescriptions for study drug in the preceding 365 days. Follow-up began on the day following the prescription fill and ended with the end of the study, the 25th birthday, loss of enrollment, death, failure to meet study inclusion/exclusion criteria, or 365 days following the last day of current use of the study psychotropic drug.

The Vanderbilt Committee for the Protection of Human Subjects and the Tennessee Bureau of Medicaid and Department of Health approved the study.

\section{Automated Database Definition for Diabetes}

The primary automated database case definition (Figure 1) began with medical care encounters that indicated possible diagnosis or treatment of diabetes, termed diabetesrelated medical care encounters. These encounters could be hospitalizations (tertiary or quaternary care settings), outpatient visits (primary or secondary care settings), or filled prescriptions for diabetes medications (Table 1). For each cohort member with such an encounter, we considered the first encounter during study follow-up.

If the encounter was a hospitalization with a primary discharge diagnosis of diabetes, the case definition was met. However, two additional steps were required for other types of encounters (Figure 1). First, cases with a diagnosis of polycystic ovarian syndrome within 120 days of the initial encounter were excluded. Polycystic ovarian syndrome was not uncommon in the study cohort, its symptoms overlap with those of diabetes, and it is often treated with oral antidiabetic drugs [19]. Second, confirmation of the initial encounter was required. Generally, a diagnosis would be confirmed by a subsequent prescription and a prescription by either a subsequent diagnosis of diabetes or by a subsequent diabetes medication prescription with a procedure indicating diabetes management (Table 1). This further confirmation was required because a single diagnosis frequently indicated a diagnostic workup and prescriptions in the absence of a diagnosis often were for polycystic ovarian syndrome.

Once the criteria for the automated database case definition were met, we assigned an index date. Generally, this was the date of the initial diabetes-related medical

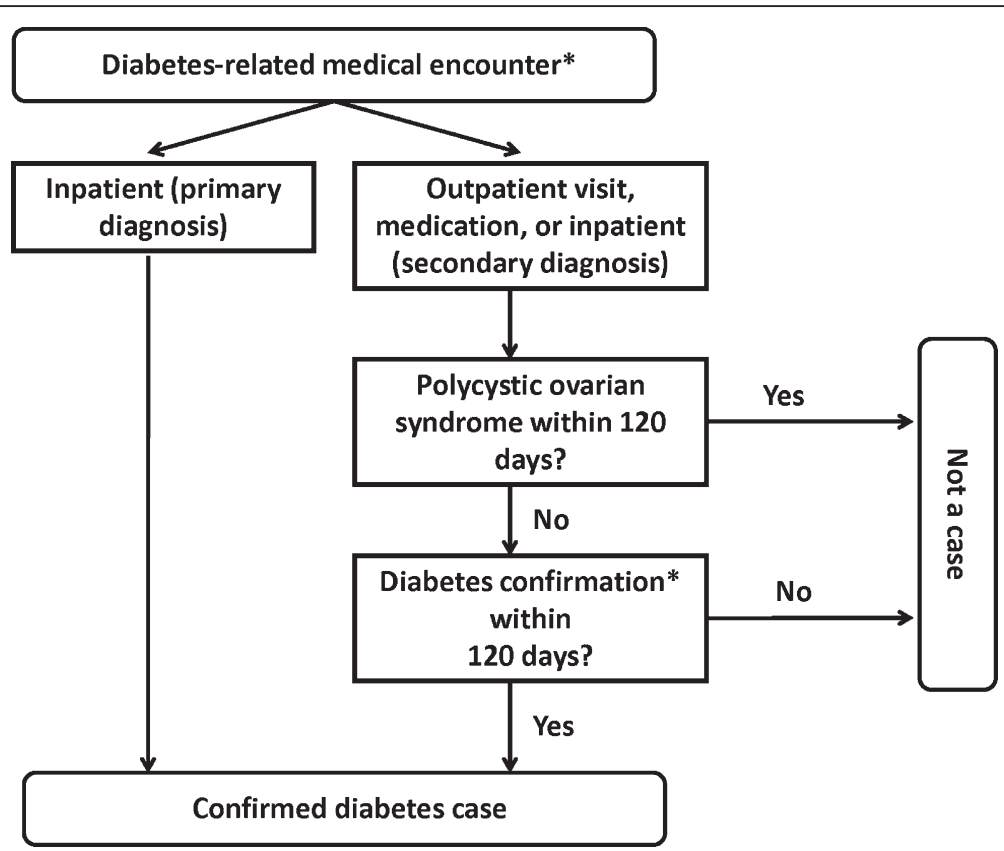

Figure 1 Automated database case definition for diabetes mellitus. ${ }^{*}$ Confirmation of initial diabetes related medical encounters were required when such encounters were identified from secondary inpatient ICD-9-CM diagnosis codes, outpatient ICD-9-CM diagnosis codes, or filled prescriptions for diabetes medications (see Table 1 for complete definitions for diabetes-related medical encounters and diabetes confirmation). Confirmation was needed in order to limit potential misclassification. Medical encounters identified from ICD-9-CM diagnosis codes were confirmed by a subsequent prescription for diabetes medications. Medical encounters identified form prescriptions were confirmed by subsequent ICD-9-CM diabetes diagnosis codes or by a subsequent diabetes medication prescription with a procedure indicating diabetes management. 
Table 1 Definitions for automated database algorithm to identify diabetes

\begin{tabular}{|c|c|c|c|c|}
\hline & Inpatient-Primary & Inpatient-Secondary & Outpatient $^{t}$ & Prescription \\
\hline \multicolumn{5}{|c|}{ Diabetes-Related Medical Care Encounter* } \\
\hline Definition & $\begin{array}{l}\text { Primary discharge diagnosis } \\
\text { of diabetes (ICD-9-CM } \\
\text { codes of } 250,250.0,250.1 \\
250.2,250.3,250.9)^{\S}\end{array}$ & $\begin{array}{l}\text { Inpatient stay with } \\
\text { 1) a secondary or admission } \\
\text { diagnosis for diabetes; or } \\
\text { 2) a physician encounter } \\
\text { with a primary diagnosis of } \\
\text { diabetes during the hospital } \\
\text { stay period, defined as the } \\
\text { day prior to admission through } \\
\text { the day following discharge. }\end{array}$ & $\begin{array}{l}\text { Outpatient visit with a } \\
\text { primary diagnosis of } \\
\text { diabetes, excluding those } \\
\text { during the hospital } \\
\text { stay period. }\end{array}$ & $\begin{array}{l}\text { Filled prescription for any } \\
\text { diabetes medication, } \\
\text { including insulin, insulin } \\
\text { adjuncts (pramlintide), } \\
\text { and oral hypoglycemics. } \\
\text { There can be no diagnosis, } \\
\text { primary or secondary, of } \\
\text { polycystic ovarian } \\
\text { syndrome in the interval } \\
{\left[t_{x}-120, t_{x}+120\right]}\end{array}$ \\
\hline $\begin{array}{l}\text { Index date }\left(\mathrm{t}_{x}\right) \\
\text { initial }\end{array}$ & $\begin{array}{l}\text { Admission date or prior } \\
\text { day if } \mathrm{ED} / \text { outpatient visit } \\
\text { with diabetes diagnosis } \\
\text { on that day }\end{array}$ & As for inpatient-primary & Day of visit & Day of prescription fill \\
\hline \multicolumn{5}{|c|}{ Additional Criteria for Diabetes Case } \\
\hline Exclusion" & None & Polycystic ovarian syndrome & & \\
\hline $\begin{array}{l}\text { Confirmation", } \\
\text { primary } \\
\text { definition }\end{array}$ & None & $\begin{array}{l}\text { 1. Diabetes medication } \\
\text { prescription, or } \\
\text { 2. Outpatient } \\
\text { or inpatient (any) } \\
\text { diagnosis }\end{array}$ & $\begin{array}{l}\text { 1. Diabetes medication } \\
\text { prescription, or } \\
\text { 2. Inpatient } \\
\text { (any) diagnosis }\end{array}$ & $\begin{array}{l}\text { 1. Outpatient or inpatient } \\
\text { (any) diagnosis, or } \\
\text { 2. Subsequent } \\
\text { prescription, and procedure } \\
\text { indicating diabetes management } \\
\text { and no diagnosis absent/ } \\
\text { irregular menses. }\end{array}$ \\
\hline $\begin{array}{l}\text { Confirmation", } \\
\text { secondary } \\
\text { definition }\end{array}$ & None & None & $\begin{array}{l}\text { Glycosylated hemoglobin } \\
\text { test (indicating possible } \\
\text { diabetes management). }\end{array}$ & As above \\
\hline Index date, fina & \multicolumn{4}{|c|}{ If diabetes-related procedure ${ }^{\#}$ in the interval $\left[t_{x}-29, t_{x}-1\right] t_{x}$ is set to procedure date. } \\
\hline
\end{tabular}

*Does not include deaths as there were none with diabetes coded as an underlying cause of death for cohort members during the study period.

${ }^{\dagger}$ Includes ED visits, but excludes case management services because these may not include patient assessment. Only primary outpatient diagnoses considered

because secondary diagnoses occurred very infrequently in the absence of a primary diagnosis and a preliminary study showed they added little predictive value.

If both a prescription and other encounter on the same day, classified as a prescription encounter. Prescriptions with a concurrent diagnosis of polycystic ovarian syndrome were not considered as diabetes-related medical care encounters, given that this disease is frequently treated with oral hypoglycemics.

Soes not include 250.4-250.8, which are chronic complications of diabetes and thus unlikely to be present for newly diagnosed cases, particularly in a population of children/youth.

"Period for exclusion or confirmation is $\left[\mathrm{t}_{\mathrm{x}}-120, \mathrm{t}_{\mathrm{x}}+120\right]$.

"Diabetes management: HbA1c (glycated hemoglobin), glucose test strips, glucose monitor, insulin pump.

\#Diabetes-related procedure: HbA1c, islet cell antibody test, insulin RIA, or metabolic panel.

care encounter. Occasionally, the date was reset to that of an earlier visit (Table 1), corresponding to the clinical scenario in which the diagnosis was not made until after the results of a test were available.

The automated database definition also classified diabetes according to clinical subtype. The case was considered type 1 diabetes if there was at least one prescription for insulin within 120 days of the index date, with no more than a single prescription for an oral hypoglycemic in that interval. The single prescription for an oral agent was allowed because, on occasion, these drugs may be prescribed while awaiting the results of confirmatory testing for type 1 diabetes. Otherwise, the case was classified as type 2 diabetes.

The primary automated database case definition essentially identified diabetes treated with pharmacotherapy. It required both diagnosis of and treatment for diabetes, unless the patient was admitted to the hospital with a primary diagnosis of diabetes. In our sample, all hospitalized cases subsequently received medications. Consequently, the primary definition did not identify patients for whom diabetes was managed without medications. Thus, we also assessed a secondary automated database definition designed to better identify such cases. This definition (Table 1) accepted secondary inpatient diagnoses without further confirmation and relaxed the requirement for confirmation of an outpatient diagnosis with a prescription, requiring only a procedure for glycosylated hemoglobin testing (indicating diabetes management).

\section{Medical record review sample}

Medical records for a sample of diabetes-related medical care encounters were reviewed to develop and validate the automated database case definition. The sample was drawn from members of the underlying cohort who had diabetesrelated medical care encounters in the 15 county region within one travel day of Nashville. Only the first encounter 
for each cohort member was considered. The sample included all encounters that met the automated database case definition and a $60 \%$ sample of other encounters.

The cohort utilized to develop the case definition included 172,014 members, of which 1,413 had a diabetes-related medical care encounter (Figure 2). Of these, 251 were in the 15 county region, of which 64 met the computer case definition and 187 did not. The medical record review sample included all of the former and $113(60.4 \%)$ of the latter (Figure 2).

\section{Adjudication procedures}

For sampled diabetes-related medical care encounters, study nurses reviewed records of all pertinent medical care within 365 days of the index date, focusing on those closest to the date of the diabetes-related encounter. They collected the results of laboratory tests, interventions undertaken, and, when appropriate, copies of

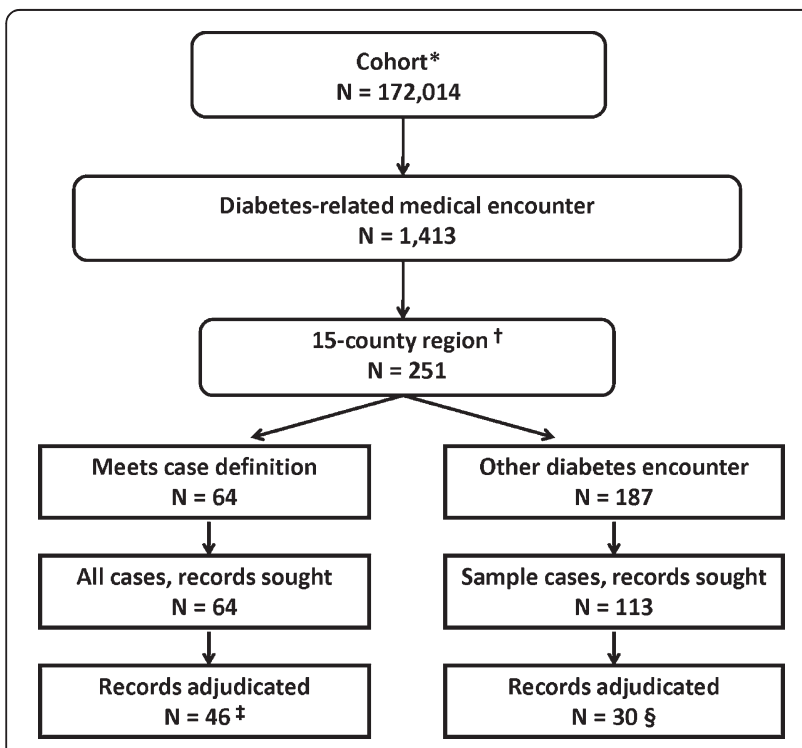

Figure 2 Sample for validation of automated database case definition for diabetes mellitus. *Preliminary version of the cohort. ${ }^{\dagger}$ Counties (State of Tennessee) included: Cannon, Cheatham, Davidson, Dickson, Hickman, Lewis, Marshall, Maury, Montgomery, Robertson, Rutherford, Sumner, Trousdale, Williamson, Wilson. ${ }^{\dagger}$ Counties (State of Tennessee) included: Cannon, Cheatham, Davidson, Dickson, Hickman, Lewis, Marshall, Maury, Montgomery, Robertson, Rutherford, Sumner, Trousdale, Williamson, Wilson. ${ }^{\star}$ There were 18 cases not adjudicated: 11--medical care provider identified, but patient record not located (most commonly for older records); 2--medical care provider not identified in Medicaid files; 2--medical care provider identified, but unable to visit (no longer practicing or relocated); 3--provider refusal. ${ }^{\$}$ There were 83 cases not adjudicated: 45--medical care provider identified, but patient record not located (most commonly for older records); 20--medical care provider not identified in Medicaid files; 11--medical care provider identified, but unable to visit (no longer practicing or relocated); 4--provider refusal 3--patient records identified but lacked sufficient information for case adjudication. medical records. All information was redacted to conceal patient identifying information. Each case was independently adjudicated by two investigators (WB,WC), masked to the exposure status of the patient, with disagreements resolved by a third reviewer (CMS).

The diagnostic criteria for diabetes required abnormal laboratory values for glycemic indices that exceeded standard cutoffs (Table 2) [20]. A non-fasting glucose value of $\geq 200 \mathrm{mg} / \mathrm{dL}$ was considered diabetes, absent an alternative recorded explanation for the elevated glucose. The adjudication did not use results of glycosylated hemoglobin tests, which recently have been accepted as a standard criterion for adults [21]. Possible diabetes was considered present if the medical record mentioned diabetes or hyperglycemia but there were no confirmatory laboratory tests (Table 2). Subthreshold hyperglycemia indicated an abnormally elevated glucose test that did not meet the criteria for diabetes (Table 2).

Diabetes cases were further adjudicated as type 1/type 2/unspecified type. We also determined the time of first diagnosis. Patients with a diagnosis prior to the first day of cohort follow-up were considered prevalent cases.

\section{Statistical methods}

The positive predictive value (PPV) of the diabetes case definition was calculated with $95 \%$ confidence intervals (CI) for binomial proportions using Wilson's formula. Case confirmation from medical record review served as the gold standard. PPV calculations were conducted using STATA statistical software, version 11.0 (STATA Corporation; College Station, Texas, USA).

Sensitivity of the primary automated database case definition were estimated. This was expressed as $a /(a+c)$, where (a) was the number of true cases identified by the definition and (c) was the number such cases that were missed [22]. The former was estimated as the number of cases in the catchment meeting the database definition times its positive predictive value. The number of missed cases was estimated as the number of diabetes-related medical encounters not meeting computer definition multiplied by the proportion of such cases that were true cases (see Additional file 1: Appendix 1 for details).

Specificity of the primary automated database case definition was also estimated. Specificity was expressed as $d /(b+d)$ where $(d)$ represents the estimated number of cases not meeting the computer case definition correctly identified as not being a diabetes case and (b) represents the estimated number of cases meeting the computer case definition misclassified as diabetes cases (see Additional file 1: Appendix 1 for details).

The study was funded by a grant from the Agency for Health Care Research and Quality, which had no role in study conduct or reporting. The listed authors were entirely responsible for study design, data analysis, 
Table 2 Clinical criteria for diabetes, subthreshold hyperglycemia, and polycystic ovarian syndrome

\begin{tabular}{|c|c|}
\hline 1. Diabetes mellitus (DM) & General criteria - any of the following: \\
\hline & 1. Fasting plasma glucose $\geq 126 \mathrm{mg} / \mathrm{dL}$ (7 mmol/L). \\
\hline & $\begin{array}{l}\text { 2. Two-hour post-prandial glucose (following } 75-\mathrm{g} \text { glucose load) } \\
\geq 200 \mathrm{mg} / \mathrm{dL}(11.1 \mathrm{mmol} / \mathrm{L}) \text {. }\end{array}$ \\
\hline & $\begin{array}{l}\text { 3. Signs or symptoms of diabetes mellitus (polyuria, polydipsia, } \\
\text { nocturia, acanthosis nigricans, weight loss, obesity/weight gain) } \\
\text { and random glucose } \geq 200 \mathrm{mg} / \mathrm{dL} \text { ( } 11.1 \mathrm{mmol} / \mathrm{L} \text { ). }\end{array}$ \\
\hline \multirow[t]{2}{*}{ 1.a. Type $1 \mathrm{DM}$} & Subtype criteria - general DM criteria (above) met, and any of the following \\
\hline & $\begin{array}{l}\text { 1. Type } 1 \text { DM diagnosis in medical record in conjunction with at least one } \\
\text { of the following: (a) insulin treatment verified in medical record; (b) C-peptide } \\
\text { concentration } \leq 0.2 \mathrm{nmol} / L_{\text {; }}^{*}(\mathrm{c}) \text { positive islet cell (ICA) or glutamic acid } \\
\text { decarboxylase antibody (GADA) assay; (d) no evidence of oral antidiabetic } \\
\text { medication use. } \\
\text { 2. Tentative type } 1 \text { DM diagnosis and any of the following: } \\
\text { (a) insulin treatment verified in medical record; (b) no evidence of oral } \\
\text { antidiabetic medication use. }\end{array}$ \\
\hline
\end{tabular}

1.b. Type $2 D M$

1.c. DM, unspecified

2. Possible DM

3. Subthreshold hyperglycemia

4. Polycystic ovarian syndrome

\section{Subtype criteria -general DM criteria (above) met, and any of the following:}

1. Type $2 \mathrm{DM}$ diagnosis in medical record in conjunction with at least one of the following: (a) oral antidiabetic medication treatment verified in medical record; (b) diabetes-targeted lifestyle modification (dietary, physical activity, other weight loss) as primary diabetes treatment verified in medical record; (c) no evidence of insulin use.

General criteria for DM met (see 1. above), but case does not meet sub-type criteria for either type 1- (see 1.a.) or type 2- (see 1.b.) DM.

Possible hyperglycemia or diabetes mellitus mentioned in record, but laboratory testing for diabetes mellitus not performed or results unknown/unavailable.

Laboratory testing for diabetes performed and results available, meeting any of the following:

1. Abnormally elevated fasting plasma glucose (100-125 mg/dL).

2. Two-hour post-prandial glucose (following 75-g glucose load) 140-199 mg/dL.

3. Abnormally elevated plasma glucose level, with or without clinical signs of diabetes mellitus, unable to verify fasting vs. non-fasting status.

\section{Any of the following:}

1. Polycystic ovarian syndrome (PCOS) diagnosis documented in medical record, with or without clinical signs and symptoms consistent with PCOS (oligomenorrhea, amenorrhea, clinical or biochemical evidence of androgen excess, or polycystic ovaries diagnosed on ultrasonography or other imaging procedure).

2. Tentative diagnosis of PCOS, with clinical signs and/or symptoms consistent with PCOS (as listed above).

*Based on diagnostic criteria used by Li et al. [36] and Bruno et al. [37].

manuscript preparation, and publication decisions; no other persons were involved. The first manuscript draft was written by the primary and senior authors, who vouch for the data and the analysis.

\section{Results}

\section{Adjudication status}

Of the 64 diabetes-related medical care encounters that met the primary automated database case definition, 46 (71.9\%) were adjudicated (Figure 2). Fifteen of the 46 adjudicated cases satisfied the case definition of type 1 diabetes, while 31 satisfied the case definition for type 2 diabetes (Table 3). For the 76 total adjudicated cases (46 adjudicated cases that met the computer case definition; 30 adjudicated cases that did not meet the computer case definition [discussed below]), 77\% were female and the mean age was 15 years.

Of the 64 diabetes-related medication encounters that met the case definition, 18 records could not be adjudicated. The most common reason for non-adjudication was inability to locate a medical record for the patient, most commonly because these were older records that had not been retained $(n=11)$. Other reasons for nonadjudication included inability to identify a care provider in the Medicaid files $(n=2)$, inability to obtain records from providers that relocated or were no longer practicing $(\mathrm{n}=2)$, and refusal of the provider to participate $(\mathrm{n}=3)$. Of the 113 sampled diabetes-related medical care encounters that did not meet the case definition, 30 (26.5\%) were adjudicated. For this group, 83 cases could not be adjudicated. The primary reason for non- 
Table 3 Adjudication status for diabetes-related medical care encounters meeting automated database definition for incident diabetes

\begin{tabular}{|c|c|c|c|}
\hline & $\begin{array}{l}\text { Computer: Diabetes } \\
\text { mellitus, any type } \\
\end{array}$ & $\begin{array}{l}\text { Computer: Type } 1 \\
\text { diabetes mellitus } \\
\end{array}$ & $\begin{array}{l}\text { Computer: Type } 2 \\
\text { diabetes mellitus } \\
\end{array}$ \\
\hline & Number (\%) & Number (\%) & Number (\%) \\
\hline Adjudicated: Total & $46(100.0)$ & $15(100.0)$ & $31(100.0)$ \\
\hline Adjudicated: Diabetes & $41(89.1)$ & $14(93.3)$ & $27(87.1)$ \\
\hline Type 1 & $13(28.3)$ & $12(80.0)$ & $1(3.2)$ \\
\hline Type 2 & $25(54.3)$ & $2(13.3)$ & $23(74.2)$ \\
\hline Unspecified type & $3(6.5)$ & $0(0.0)$ & $3(9.7)$ \\
\hline Adjudicated: Not Incident Diabetes & $5(10.9)$ & $1(6.7)$ & $4(12.9)$ \\
\hline Prevalent diabetes & $1(2.2)$ & $1(6.7)$ & $0(0.0)$ \\
\hline Subthreshold hyperglycemia & $3(6.5)$ & $0(0.0)$ & $3(9.7)$ \\
\hline Polycystic ovarian syndrome & $1(2.2)$ & $0(0.0)$ & $1(3.2)$ \\
\hline
\end{tabular}

adjudication also was inability to locate the patient's medical record $(n=45)$; other reasons included inability to identify a care provider in the Medicaid files $(n=20)$, inability to obtain records from providers that relocated or were no longer practicing $(n=11)$, provider refusal $(\mathrm{n}=4)$, and insufficient information for case adjudication $(n=3)$.

\section{Overall performance of case definition}

Of the 46 adjudicated cases meeting the primary automated database definition for diabetes, 41 were adjudicated as diabetes with onset beginning during cohort follow-up (Table 3), resulting in a positive predictive value of $89.1 \%$ (95\% CI 77.0, 95.3\%). The five cases not adjudicated as diabetes included three cases of subthreshold hyperglycemia (Table 3; defined in Table 2), one case of diabetes with onset before $t_{0}$, and one case of polycystic ovarian syndrome. The estimated sensitivity of the primary automated database definition for diabetes was $64.8 \%$, while the specificity of the primary case definition was $>99 \%$.

\section{Case definition performance by diabetes subtype}

We also calculated the performance of the automated database case definition according to type of diabetes (Table 3). Of the 41 cases meeting the case definition adjudicated as diabetes, 13 were adjudicated as type 1, 25 were adjudicated as type 2 and for 3 the type was unspecified. The positive predictive value of the computer case definition for type 1 diabetes was $80.0 \%$ (95\% CI $54.8,93.0 \%$ ) and that for type 2 was $74.2 \%$ (95\% CI 56.8 , $86.3 \%)$. When those cases for which type was unspecified were considered as type 2, the positive predictive value of the automated database definition for type 2 was $83.9 \%$ (95\% CI 67.4, 92.9\%).

\section{Cases that Did Not meet diabetes case definition}

Of the 30 adjudicated cases that did not meet the primary automated database case definition, 5 (16.7\%) were adjudicated as diabetes (Table 4). The other cases most commonly were possible diabetes (Table 2), subthreshold hyperglycemia, and polycystic ovarian syndrome (all treated with an oral hypoglycemic). The five confirmed cases had index diabetes-related medical care encounters that were outpatient visits (four cases) or secondary inpatient (one case) diagnoses; none was identified from a filled prescription.

\section{Performance of secondary diabetes case definition}

We also assessed the performance of a secondary automated database case definition designed to better identify diabetes not treated with medications (Additional file 1: Appendix Table 1 and Additional file 1: Appendix Table 2; Additional file 1: Appendix Figure 1). The positive predictive value of this definition was $75.9 \%$ (95\% CI $63.5,85.0 \%)$ and the estimated sensitivity was $81.1 \%$ (95\% CI 54.4, 73.9\%).

\section{Discussion}

We developed an algorithm to identify newly diagnosed cases of diabetes in children and youth that utilized automated database medical care encounter records. The primary automated database case definition, which generally required both diagnosis of and pharmacotherapy for diabetes, was validated by review of medical records with application of an objective standard for diabetes. In the sample studied, the positive predictive value for definite/probable diabetes was $89 \%$ and the case definition reliably distinguished between type 1 and type 2 diabetes. The estimated sensitivity was $65 \%$. A secondary definition that better captured diabetes not treated with 
Table 4 Adjudication status for diabetes-related medical care encounters not meeting the automated database definition for incident diabetes, by type of medical encounter

\begin{tabular}{|c|c|c|c|c|}
\hline & Inpatient, secondary diagnosis & Outpatient diagnosis & Filled prescription & Any medical encounter type \\
\hline & Number (\%) & Number (\%) & Number (\%) & Number (\%) \\
\hline Adjudicated: Total & $4(100.0)$ & $11(100.0)$ & $15(100.0)$ & $30(100.0)$ \\
\hline Adjudicated: Diabetes & $1(25.0)$ & $4(36.4)$ & $0(0.0)$ & $5(16.7)$ \\
\hline Adjudicated: Not Diabetes & $3(75.0)$ & $7(63.6)$ & $15(100.0)$ & $25(83.3)$ \\
\hline Prevalent diabetes & $0(0.0)$ & $0(0.0)$ & $1(6.7)$ & $1(3.3)$ \\
\hline Possible diabetes & $1(25.0)$ & $1(9.1)$ & $5(33.3)$ & $7(23.3)$ \\
\hline Subthreshold hyperglycemia & $1(25.0)$ & $4(36.4)$ & $2(13.3)$ & $7(23.3)$ \\
\hline Polycystic ovarian syndrome & $0(0.0)$ & $0(0.0)$ & $6(20.0)$ & $6(20.0)$ \\
\hline Laboratory test, rule-out & $0(0.0)$ & $1(9.1)$ & $1(6.7)$ & $2(6.7)$ \\
\hline Miscoded diagnosis & $1(25.0)$ & $1(25.0)$ & $0(0.0)$ & $2(6.7)$ \\
\hline
\end{tabular}

medications had a positive predictive value of $76 \%$ and an estimated sensitivity of $81 \%$.

The availability of a valid computer case definition of new-onset type 2 diabetes is crucial for conducting pharmacoepidemiologic studies of type 2 diabetes as a study endpoint using automated databases. Automated databases may be the only efficient means of quantifying type 2 diabetes risk associated with specific drug exposures, given how infrequently it occurs. However, there are several challenges to conducting pharmacoepidemiologic studies using automated databases. Among the most serious of these is the potential for bias from endpoint misclassification due to coding errors or other problems [16,17]. Most automated databases, including the one used in our study, include medical encounter and healthcare service utilization data that were not collected specifically for research purposes. As such, the quality of the collected data may vary considerably [17]. In one study that used ICD-9 diagnosis codes from one or more outpatient records in the U.S. Indian Health Service Facility Database to estimate the prevalence and incidence of diabetes in Navajo youth, a diagnosis of diabetes was confirmed in less than $50 \%$ of cases [23]. The primary reason for misclassification was coding errors.

In our study, the most common source of misclassification was subthreshold hyperglycemia, accounting for $6 \%$ and $14 \%$ of adjudicated cases that respectively met the primary or secondary case definitions. These cases had an abnormal glucose laboratory value that was below the standard cutpoint for diabetes. This may represent in part the treatment of "prediabetes" [24], an increasingly common, yet controversial, trend among adults [25]. Although such cases might reflect adverse metabolic effects of medications, such as increased weight, we nevertheless considered them as false positives, given that the pathophysiology of drug-induced diabetes is incompletely understood [26].
We chose positive predictive value as the primary measure of algorithm performance based on our objective to develop and validate a computer case definition to facilitate pharmacoepidemiologic investigations of medications and the risk of new-onset diabetes. Determining sensitivity would quantify performance of our case definition only for those already known to have new-onset diabetes. In automated database studies, suspected (not established) cases of new-onset diabetes would be first identified. The positive predictive value is an ideal measure under this circumstance, as it represents the proportion of true cases among those identified by the computer algorithm as potential cases. Our results suggest that a high proportion of potential cases identified by our algorithm will be true cases.

Prior studies of the association between medications and new-onset diabetes in adults $[27,28]$ have utilized validated case definitions based upon both diabetes diagnoses and prescriptions, which have been found to have good positive predictive value [29]. However, there are important differences for children and youth. First, type 1 diabetes has a much higher incidence. Distinguishing type 2 diabetes, the primary concern with respect to medication effects, must be considered for studies of younger populations. Distinguishing between type 1 and type 2 diabetes in the young is complicated, however, by the ever-increasing epidemic of overweight/obesity and other risk factors for insulin resistance in this population [30], which may result in misdiagnosis or substantial delays in arriving at a definitive diagnosis [31]. These factors make it difficult to differentiate type 1 and type 2 diabetes in youth using administrative data. Administrative data algorithms that rely on ICD-9 or -10 diagnosis codes for detecting diabetes in children or youth have been shown to capture type 1 diabetes more reliably than type 2 diabetes cases [32,33]. Although there are separate ICD-9-CM diagnostic codes for each type of diabetes, we and others [33] have found these to have 
little predictive value. The most reliable way to identify type 2 diabetes in our sample was to remove cases with a filled prescription for insulin, in the absence of repeated oral hypoglycemic prescriptions. Another unique aspect of populations with large numbers of women of reproductive age is the occurrence of polycystic ovarian syndrome, which, in our sample, often was indicated by a prescription for an oral hypoglycemic without a diagnosis of diabetes. In a recently published retrospective cohort study of diabetes incidence in children and adolescents that used antidiabetic drug prescriptions as a proxy for the disease itself, $22 \%$ of children who were prescribed metformin received the drug for treatment of polycystic ovarian syndrome [34].

Our primary automated database case definition focused on diabetes treated with pharmacotherapy, an important clinical consideration given that many individuals with type 2 diabetes will be treated with lifestyle interventions alone [35]. Our focus on medicallytreated diabetes may have resulted in approximately one-third of the estimated total cases in the study sample being missed. Thus, we also assessed a secondary definition designed to better detect diabetes that was not treated with medications. The estimated sensitivity of this definition improved to $81 \%$; however, the positive predictive value fell from $89 \%$ to $76 \%$. The drop in the positive predictive value was primarily due to the misclassification of subthreshold hyperglycemia ( $14 \%$ of adjudicated cases) as diabetes.

\section{Limitations}

The automated database case definition was developed and validated in a single sample that consisted of Tennessee Medicaid enrollees who had recently initiated therapy with a psychotropic medication. Although the algorithm has face validity, over-fitting is possible. Given these limitations, the performance of our algorithm in this cohort may not be generalizable to other patient populations, including Medicaid populations in other states and in non-psychiatric populations. Further investigations in other clinical settings and populations are needed.

We were unable to abstract and adjudicate $100 \%$ of all records sought that met the computer case definition of diabetes. Bias in our PPV estimate would be possible, particularly if there were systematic differences in the accuracy or quality of ICD-9 diagnosis coding, patterns of clinical practice, or clinical documentation between records that could be abstracted and those that could not. Under these circumstances, one would be less reassured that abstracted cases were representative of the source population. We were able to abstract and adjudicate nearly $72 \%$ of records for cases that met the diabetes computer case definition, and the most common reason for not being able to abstract such records was that records were too old to be retained by the practices. While these points provide some reassurance, we cannot exclude completely the possibility that systematic differences between abstracted and non-abstracted cases could have occurred, thus introducing potential bias in our PPV estimate.

Our estimate of the sensitivity of the automated database case definition relied upon adjudication of a sample of cases with diabetes-related medical care encounters that did not meet the database definition. We were only able to adjudicate $27 \%$ of the potential cases in this sample. The primary reason for the low rate of adjudication was that most of these consisted of a single prescription or outpatient diagnosis. In this circumstance, we often were unable to find the record for the individual patient, most commonly because these were older records that had not been retained in the practice. However, given that diabetes is a chronic disease, it seems unlikely that these isolated encounters represent true cases.

Finally, the "gold standard" for diabetes in the study sample was based upon review of medical care provider records. Although laboratory values were required for adjudication of a case as diabetes [36,37], standardized fasting glucose or glucose challenge tests were not uniformly obtained.

\section{Conclusion}

We developed and validated an automated database case definition for newly diagnosed diabetes. The definition had an overall positive predictive value of $89 \%$ for definite/probable diabetes and could distinguish between type 1 and type 2 diabetes. If our findings are replicated in other settings, our algorithm could be a useful endpoint for pharmacoepidemiological studies that focus on the risk of medication-associated new-onset diabetes mellitus.

\section{Additional file}

Additional file 1: Appendix 1. Calculation of Sensitivity and Specificity Estimates; Appendix Table 1. Secondary Automated Database Diabetes Definition: Adjudication status for diabetes-related medical care encounters meeting automated database definition for incident diabetes. Appendix Table 2. Secondary Automated Database Diabetes Definition: Adjudication status for diabetes-related medical care encounters not meeting the automated database definition for incident diabetes, by type of medical encounter. Appendix Figure 1. Secondary Automated Database Diabetes Definition: Validation sample.

\section{Competing interests}

This study was supported in part by the Agency for Healthcare Research and Quality (AHRQ), Centers for Education and Research on Therapeutics (HS1-0384), and CERT consortium grant (5U18HS017918-02). WVB is supported by a National Institute of Mental Health grant K23MH087747. The funders had no role in study design, data collection and analysis, decision to publish, or preparation of the manuscript. The study authors have not had in the previous 12 months a relevant duality of interest to disclose. 


\section{Authors' contributions}

WVB, WOC and WAR conceived and designed the study. WVB, WOC, JM and $J D$ researched data. WOC and JM participated in the coordination of the study. WVB and WAR drafted the manuscript. All authors contributed to, read, and approved the manuscript in its final version.

\section{Acknowledgments}

We are indebted to Leanne Balmer, RN, Vanderbilt University School of Medicine, who assisted with medical records abstraction. We gratefully acknowledge the Tennessee Bureau of TennCare and Department of Health, which provided study data.

\section{Author details}

'Department of Psychiatry, Vanderbilt University School of Medicine, 1500 21st Ave South, Suite 2200 Village at Vanderbilt, Nashville, TN, 37212, USA. 2 Department of Pediatrics, Vanderbilt University School of Medicine, Nashville, TN, 37212, USA. ${ }^{3}$ Division of Clinical Pharmacology, Department of Internal Medicine, Vanderbilt University School of Medicine, Nashville, TN, 37212, USA. ${ }^{4}$ Department of Psychiatry, Columbia University College of Physicians and Surgeons, New York, NY, USA. ${ }^{5}$ Division of

Pharmacoepidemiology, Department of Preventive Medicine, Vanderbilt University School of Medicine, Nashville, TN, 37212, USA. ${ }^{6}$ Geriatric Research, Education and Clinical Center, Veterans Administration Tennessee Valley Health Care System, Nashville, TN, 37212, USA.

Received: 25 January 2012 Accepted: 20 August 2012

Published: 24 August 2012

\section{References}

1. Fagot-Campagna A, Pettitt DJ, Engelgau MM, Burrows NR, Geiss LS, Valdez R, Beckles GL, Saaddine J, Gregg EW, Williamson DF, Narayan KM: Type 2 diabetes among North American children and adolescents: an epidemiologic review and a public health perspective. J Pediatr 2000, 136(5):664-672.

2. Pinhas-Hamiel O, Zeitler P: The global spread of type 2 diabetes mellitus in children and adolescents. J Pediatr 2005, 146(5):693-700.

3. Voight BF, Scott LJ, Steinthorsdottir V, Morris AP, Dina C, et al: Twelve type 2 diabetes susceptibility loci identified through large-scale association analysis. Nat Genet 2010, 42(7):579-589.

4. Herder C, Roden M: Genetics of type 2 diabetes: pathophysiologic and clinical relevance. Eur J Clin Invest 2011, 41(6):679-692.

5. Nettleton JA, McKeown NM, Kanoni S, Lamaitre RN, Hivert MF, et al: Interactions of dietary whole-grain intake with fasting glucose- and insulin-related genetic loci in individuals of European descent: a meta-analysis of 14 cohort studies. Diabetes Care 2010, 33(12):2684-2691.

6. Hu FB, Manson JE, Stampfer MJ, Colditz G, Liu S, Solomon CG, Willett WC: Diet, lifestyle, and the risk of type 2 diabetes mellitus in women. $N$ Engl J Med 2001, 345(11):790-797.

7. Knowler WC, Fowler SE, Hamman RF, Christophi CA, Hoffman HJ, Brenneman AT, Brown-Friday JO, Goldberg R, Benditti E, Nathan DM: 10-year follow-up of diabetes incidence and weight loss in the Diabetes Prevention Program Outcomes Study. Lancet 2009, 374(9702):1677-1686.

8. Gillies CL, Abrams KR, Lambert PC, Cooper NJ, Sutton AJ, Hsu RT, Kjunti K: Pharmacological and lifestyle interventions to prevent or delay type 2 diabetes in people with impaired glucose tolerance: systematic review and meta-analysis. BMJ 2007, 334(7588):299.

9. Hectors TL, Vanparys $C$, van der Ven K, Martens GA, Jorens PG, van Gaal LF, Covaci A, De Coen W, Blust R: Environmental pollutants and type 2 diabetes: a review of mechanisms that can disrupt beta cell function. Diabetologia 2011, 54(6):1273-1290.

10. Newcomer JW: Second-generation (atypical) antipsychotics and metabolic effects: a comprehensive literature review. CNS Drugs 2005, 19(Suppl 1):1-93.

11. McIntyre RS, Jerrell JM: Metabolic and cardiovascular adverse events associated with antipsychotic treatment in children and adolescents. Arch Pediatr Adolesc Med 2008, 162(10):929-935.

12. Correll CU, Carlson HE: Endocrine and metabolic adverse effects of psychotropic medications in children and adolescents. J Am Acad Child Adolesc Psychiatry 2006, 45(7):771-791.
13. Beckman JA, Creager MA, Libby P: Diabetes and atherosclerosis: epidemiology, pathophysiology, and management. JAMA 2002, 287(19):2570-2581.

14. Bowden DW, Cox AJ, Freedman Bl, Hugenschimdt CE, Wagenknecht LE, Herrington D, Agarwal S, Register TD, Maldjian JA, Ng MC, Hsu FC, Langefeld CD, Williamson JD, Carr JJ: Review of the Diabetes Heart Study (DHS) family of studies: a comprehensively examined sample for genetic and epidemiological studies of type 2 diabetes and its complications. Rev Diabet Stud 2010, 7(3):188-201.

15. Pinhas-Hamiel O, Zeitler P: Acute and chronic complications of type 2 diabetes mellitus in children and adolescents. Lancet 2007, 369(9575):1823-1831.

16. Ray WA: Population-based studies of adverse drug effects. N Engl J Med 2003, 349(17):1592-1594.

17. Ray WA: Improving automated database studies. Epidemiology 2011, 22(3):302-304.

18. Ray WA, Griffin MR: Use of Medicaid data for pharmacoepidemiology. Am J Epidemiol 1989, 129(4):837-849.

19. Geller DH, Pacaud D, Gordon CM, Misra M: The use of insulin sensitizers in the treatment of adolescents with polycystic ovary syndrome (PCOS). Int J Pediatr Endocrinol 2011, 11:9.

20. American Diabetes Association: Standards of medical care in diabetes2011. Diabetes Care 2011, 34(Suppl 1):S11-S61.

21. American Diabetes Association: Diagnosis and classification of diabetes mellitus. Diabetes Care 2010, 33(Suppl 1):S62-S69.

22. Haynes RB, Sackett DL, Guyatt GH, Tigwell P: Clinical Epidemiology. 3rd edition. New York: Lippincott Williams \& Wilkins; 2006.

23. Dabelea D, DeGroat J, Sorrelman C, Glass M, Percy CA, Avery C, Hu D, D'Agostino RB, Beyer J, Imperatore G, Testaverde L, Klingensmith G, Hamman RF: Diabetes in Navajo youth. Diabetes Care 2009, 32(Suppl 2): S141-S137.

24. Unwin N, Shaw J, Zimmet P, Alberti KG: Impaired glucose tolerance and impaired fasting glycaemia: the current status on definition and intervention. Diabet Med 2002, 19(9):708-723.

25. Colagiuri S: Epidemiology of prediabetes. Med Clin North Am 2011, 95(2):299-307.

26. Coccurello $R$, Moles A: Potential mechanisms of atypical antipsychotic-induced metabolic derangement: clues for understanding obesity and novel drug design. Pharmacol Ther 2010, 127(3):210-251.

27. Lambert BL, Cunningham FE, Miller DR, Dalack GW, Hur K: Diabetes risk associated with use of olanzapine, quetiapine, and risperidone in veterans health administration patients with schizophrenia. Am J Epidemiol 2006, 164(7):672-681.

28. Solomon DH, Massarotti E, Garg R, Liu J, Canning C, Schneeweiss S: Association between disease-modifying antirheumatic drugs and diabetes risk in patients with rheumatoid arthritis and psoriasis. JAMA 2011, 305(24):2525-2531.

29. Miller DR, Safford MM, Pogach LM: Who has diabetes? Best estimates of diabetes prevalence in the Department of Veterans Affairs based on computerized patient data. Diabetes Care 2004, 27(Suppl 2):B10-B21.

30. Bloomgarden ZT: Type 2 diabetes in the young: the evolving epidemic. Diabetes Care 2004, 27(4):998-1010.

31. Rosenbloom AL, Silverstein $\mathrm{H}$, Amemiya S, Zeitler P, Klingensmith GJ: ISPAD Clinical Practice Consensus Guidelines 2006-2007: Type 2 diabetes mellitus in the child and adolescent. Pediatric Diabetes 2008, 9(5):512-526.

32. Dart A, Martens PJ, Sellers EA, Brownell MD, Rigatto C, Dean HJ: Validation of a pediatric diabetes case definition using administrative health data in Manitoba, Canada. Diabetes Care 2011, 34(4):898-903.

33. Rhodes ET, Laffel LM, Gonzalez TV, Ludwig DS: Accuracy of administrative coding for type 2 diabetes in children, adolescents, and young adults. Diabetes Care 2007, 30(1):141-143.

34. Hsia Y, Neubert AC, Rani F, Viner RM, Hindmarsh PC, Wong IC: An increase in the prevalence of type 1 and 2 diabetes in children and adolescents: results from prescription data from a UK general practice database. $\mathrm{Br} J$ Clin Pharmacol 2009, 67(2):242-249.

35. Rosenbloom AL: Increasing incidence of type 2 diabetes in children and adolescents: treatment considerations. Paediatric Drugs 2002, 4(4):209-221. 
36. Li H, Isomaa B, Taskinen MR, Groop L, Tuomi T: Consequences of a family history of type 1 and type 2 diabetes on the phenotype of patients with type 2 diabetes. Diabetes Care 2000, 23(5):589-594.

37. Bruno G, Runzo C, Cavallo-Perin P, Merletti F, Rivetti M, Pinach S, Novelli G, Trovati M, Cerutti F, Pagano G: Piedmont Study Group for Diabetes Epidemiology: Incidence of type 1 and type 2 diabetes in adults aged 30-49 years: the population-based registry in the province of Turin, Italy. Diabetes Care 2005, 28(11):2613-2619.

doi:10.1186/1471-2288-12-128

Cite this article as: Bobo et al.: Positive predictive value of a case definition for diabetes mellitus using automated administrative health data in children and youth exposed to antipsychotic drugs or control medications: a Tennessee Medicaid study. BMC Medical Research Methodology 2012 12:128.

\section{Submit your next manuscript to BioMed Central and take full advantage of:}

- Convenient online submission

- Thorough peer review

- No space constraints or color figure charges

- Immediate publication on acceptance

- Inclusion in PubMed, CAS, Scopus and Google Scholar

- Research which is freely available for redistribution 